\title{
WOMEN'S VIEWS ON Prescription Drugs
}

July 2021

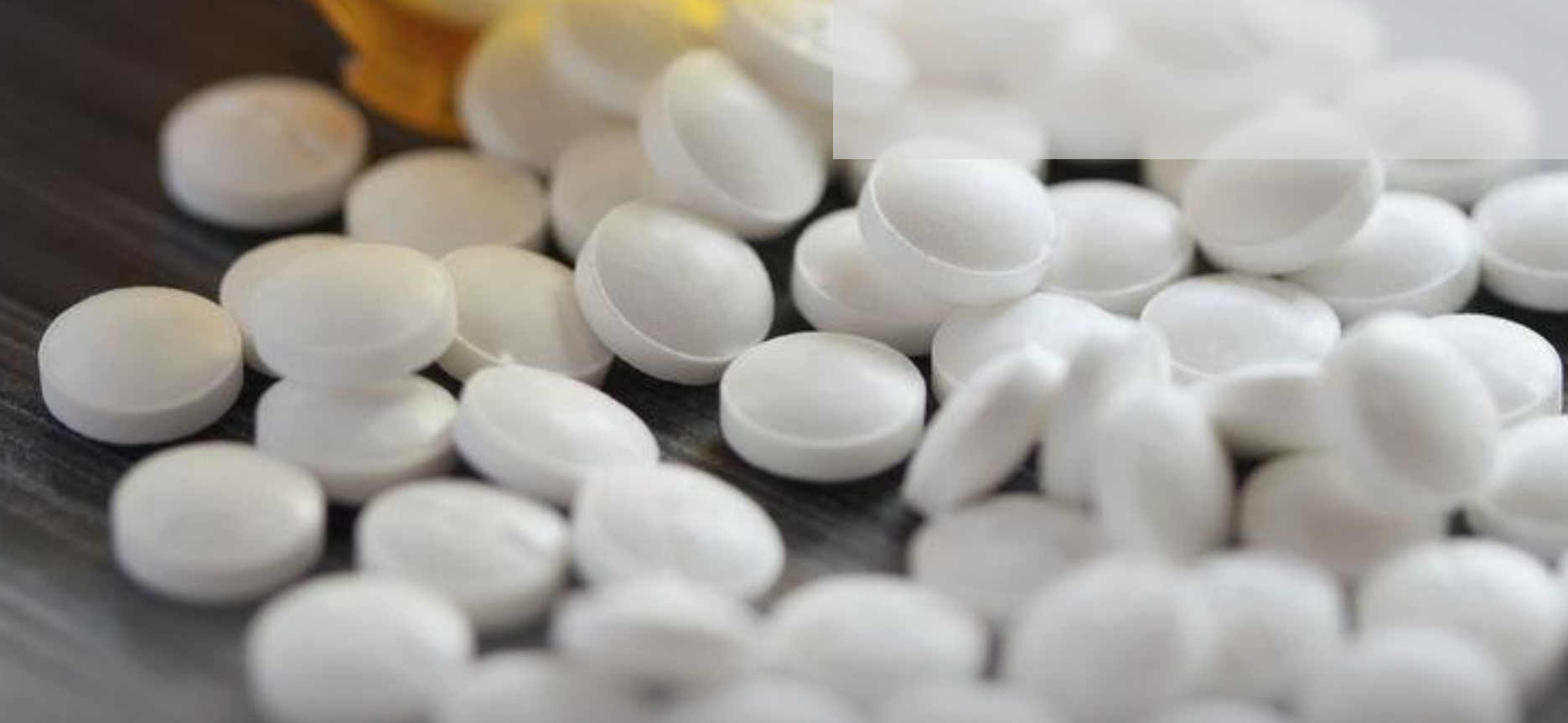




\section{Key Findings}

- Most women voters 50-plus take prescriptions and refill them regularly; cost is the top reason cited for not filling a prescription, with about half as many women citing concerns about side effects.

- Women are more likely than men to express high levels of concern about the affordability of prescription drugs.

- Most voters 50+ believe U.S. consumers pay more for the same Rx drugs than do consumers in other countries, with no differences by gender.

- Support is consistently high for all five legislative proposals related to lowering the prices of prescription drugs, with women more likely to favor penalizing drug companies that raise prices above inflation.

- Six in ten voters 50+ disagree that innovation will suffer if Medicare negotiates for lower prices making it harder to get lifesaving drugs to market.

- Eight in ten voters $50+$ agree that drug prices can be lowered without harming the innovation of new medicines, with no differences by gender.

- Women are more likely than men to strongly or somewhat agree that Congress needs to take action to lower prescription drug prices.

- Successful COVID-19 vaccine negotiations increase voters' agreement that government should negotiate for lower prices for other drugs, with no differences by gender.

- Women voters 50+ are more likely to consider Presidential/Congressional agreement on lowering Rx drug prices as very or somewhat important.

- Most voters 50-plus would be more favorable to a member of Congress who supports legislation to lower drug prices, with no differences by gender. 


\section{Most women voters 50-plus take prescriptions and refill them regularly; cost is top reason for not filling a prescription.}

Take prescription drugs regularly?

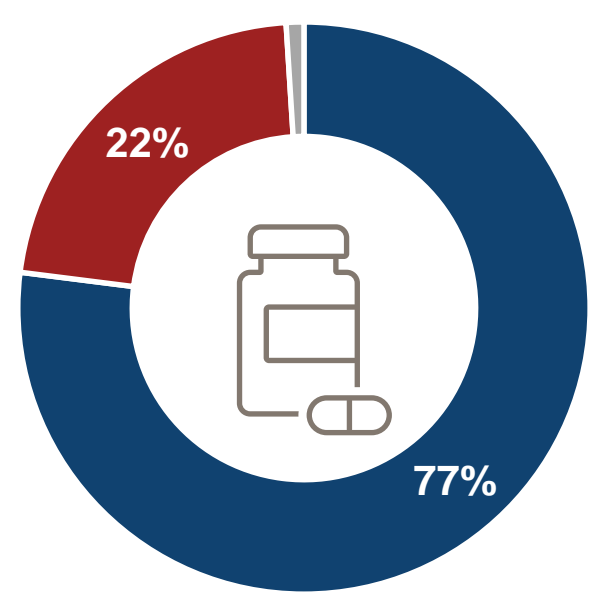

-Yes - No - Don't know/ref.
Decided to not fill Rx?

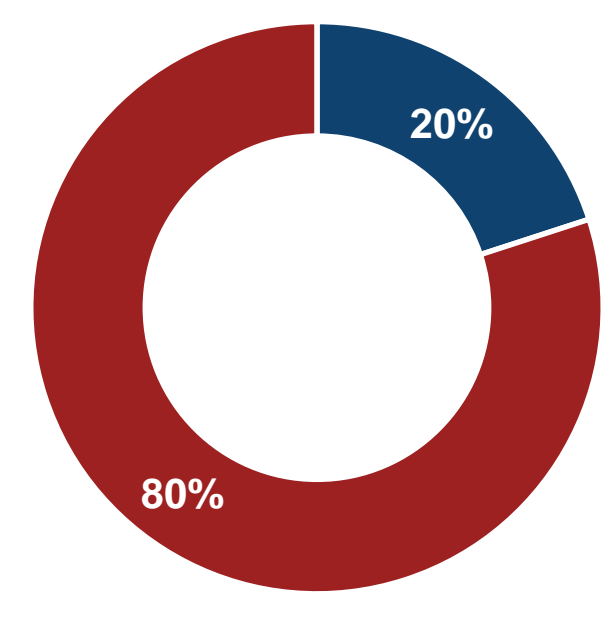

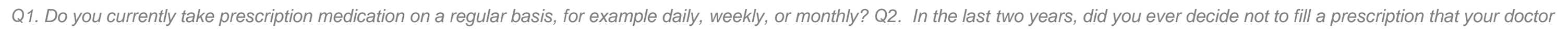
had given you? (Base: Women voters 50+: $n=533$ ) Q3. What were the reasons you didn't fill your prescription? (Base: Those who did not fill a prescription $n=109 *$ small sample) 


\section{Women are more likely than men to express high levels of concern about the affordability of prescription drugs.}

Concern About Affordability of Prescriptions, by Gender

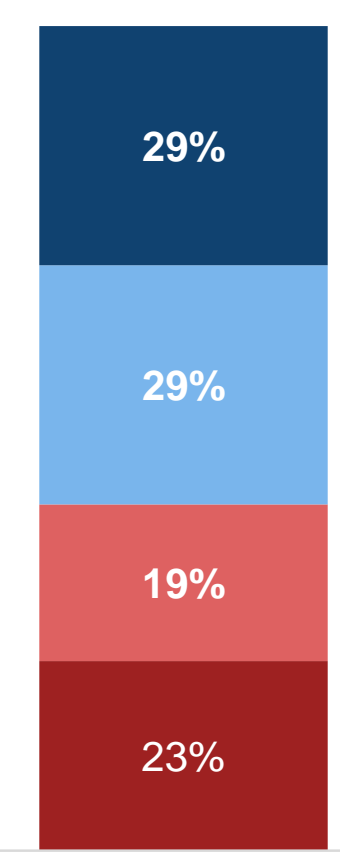

Total $50+(n=1,000)$

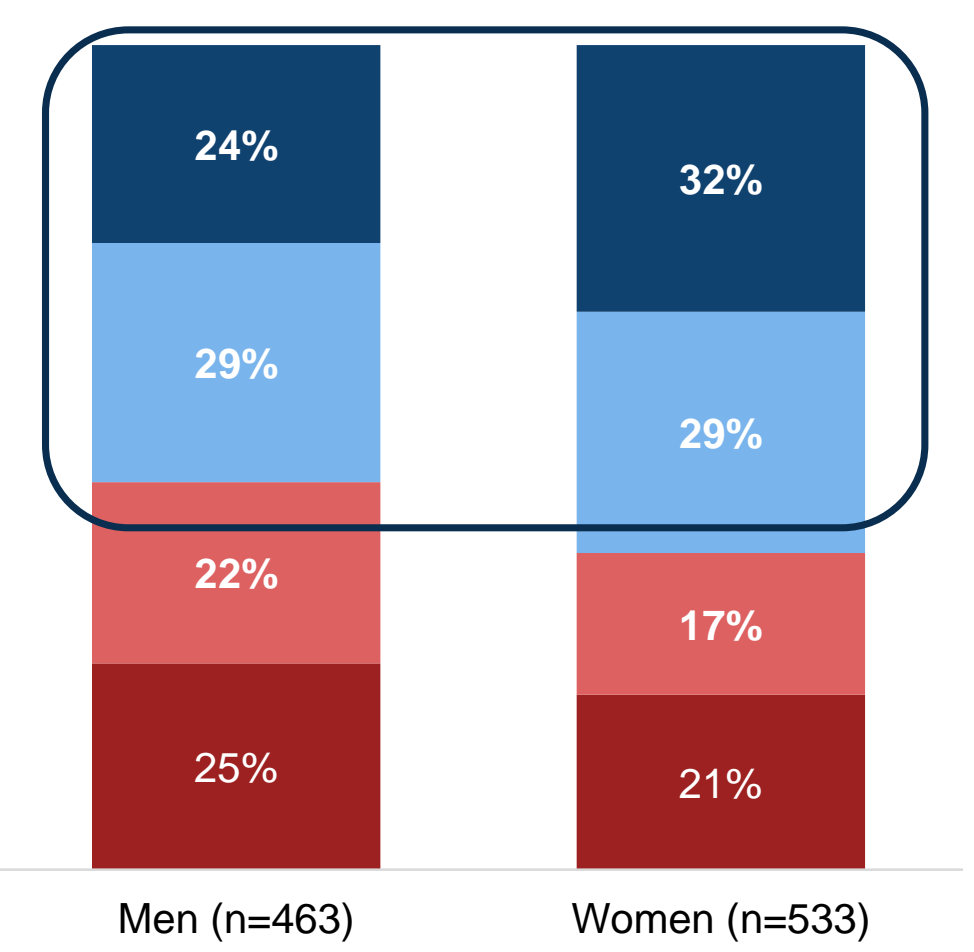

- Very concerned

- Somewhat concerned

- Not very concerned

- Not at all concerned

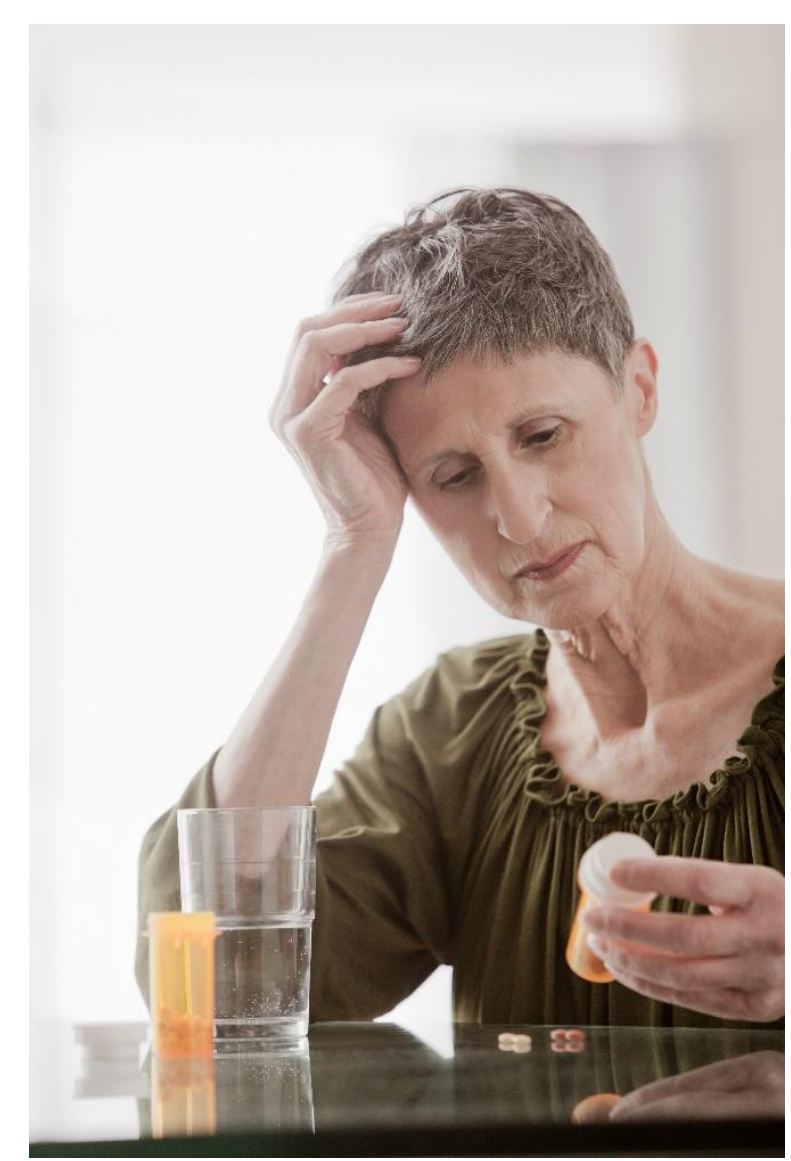




\section{Most voters $50+$ believe U.S. consumers pay more for the same Rx drugs than do consumers in other countries, with no differences by gender.}

Perceived Prices of Drugs Paid in U.S. Compared to that Paid in Other Countries

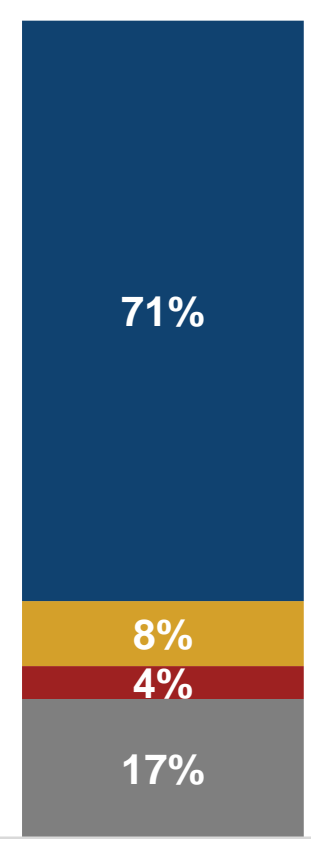

Total $50+(n=1,000)$

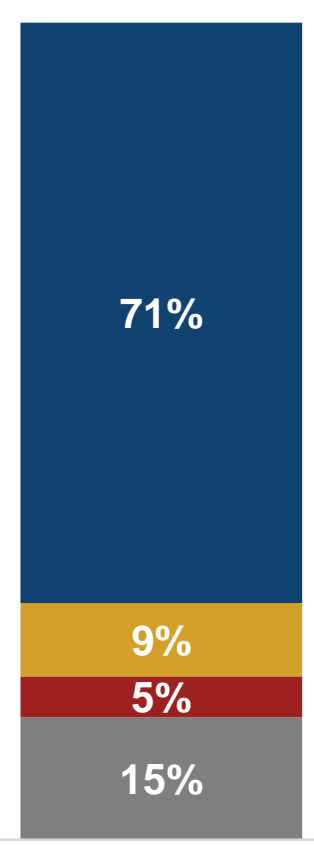

Men $(n=463)$

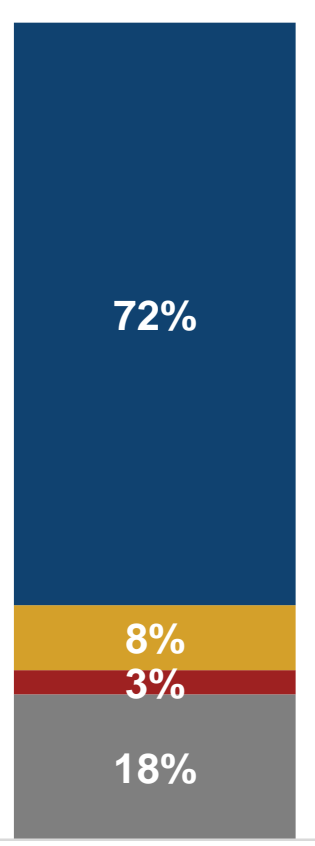

Women $(n=533)$
- More

About the same

- Less

- Don't know/

refused

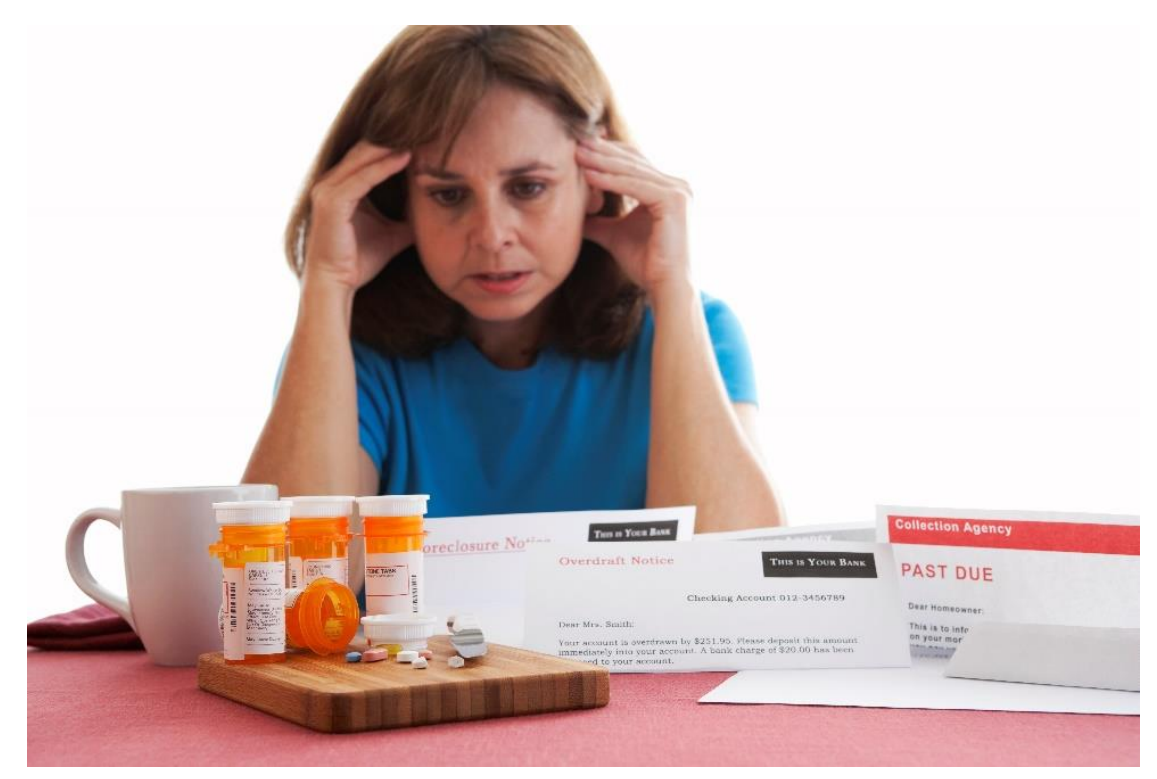

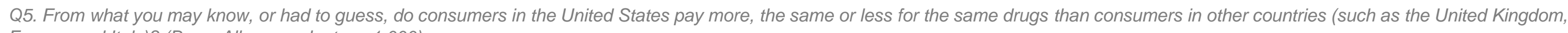
France, and Italy)? (Base: All respondents $n=1,000$ ) 


\section{Support is consistently high for all five legislative proposals, with women more likely to favor penalizing drug companies that raise prices above inflation.}

\section{Support for Proposals to Lower Prescription Drug Prices, by Gender (Percent 'Favor')}

\begin{tabular}{|c|c|c|c|}
\hline By Political Party & Total & Men & Women \\
\hline & $n=1,000$ & $n=463$ & $n=533$ \\
\hline $\begin{array}{l}\text { Allow Medicare, the largest prescription drug purchaser in the U.S., to negotiate with } \\
\text { drug companies for lower prices }\end{array}$ & $87 \%$ & $87 \%$ & $87 \%$ \\
\hline $\begin{array}{l}\text { Put a cap on the amount seniors have to pay out of pocket every year for their } \\
\text { prescription drugs }\end{array}$ & $78 \%$ & $75 \%$ & $80 \%$ \\
\hline $\begin{array}{l}\text { Prevent drug companies from charging more for drugs in the United States than they do } \\
\text { in other countries }\end{array}$ & $77 \%$ & $73 \%$ & $80 \%$ \\
\hline $\begin{array}{l}\text { Close the loopholes that allow brand-name pharmaceutical companies to charge high } \\
\text { prices for new drugs that are simply copycats or minor improvements over existing } \\
\text { drugs }\end{array}$ & $74 \%$ & $72 \%$ & $76 \%$ \\
\hline Penalize drug companies that raise their prices higher than inflation & $71 \%$ & $65 \%$ & $75 \%$ \\
\hline
\end{tabular}


Six in ten voters $50+$ disagree that innovation will suffer if Medicare negotiates for lower prices making it harder to get lifesaving drugs to market.

Agreement that 'Innovation Will Suffer if Medicare Negotiates For Lower Prices'
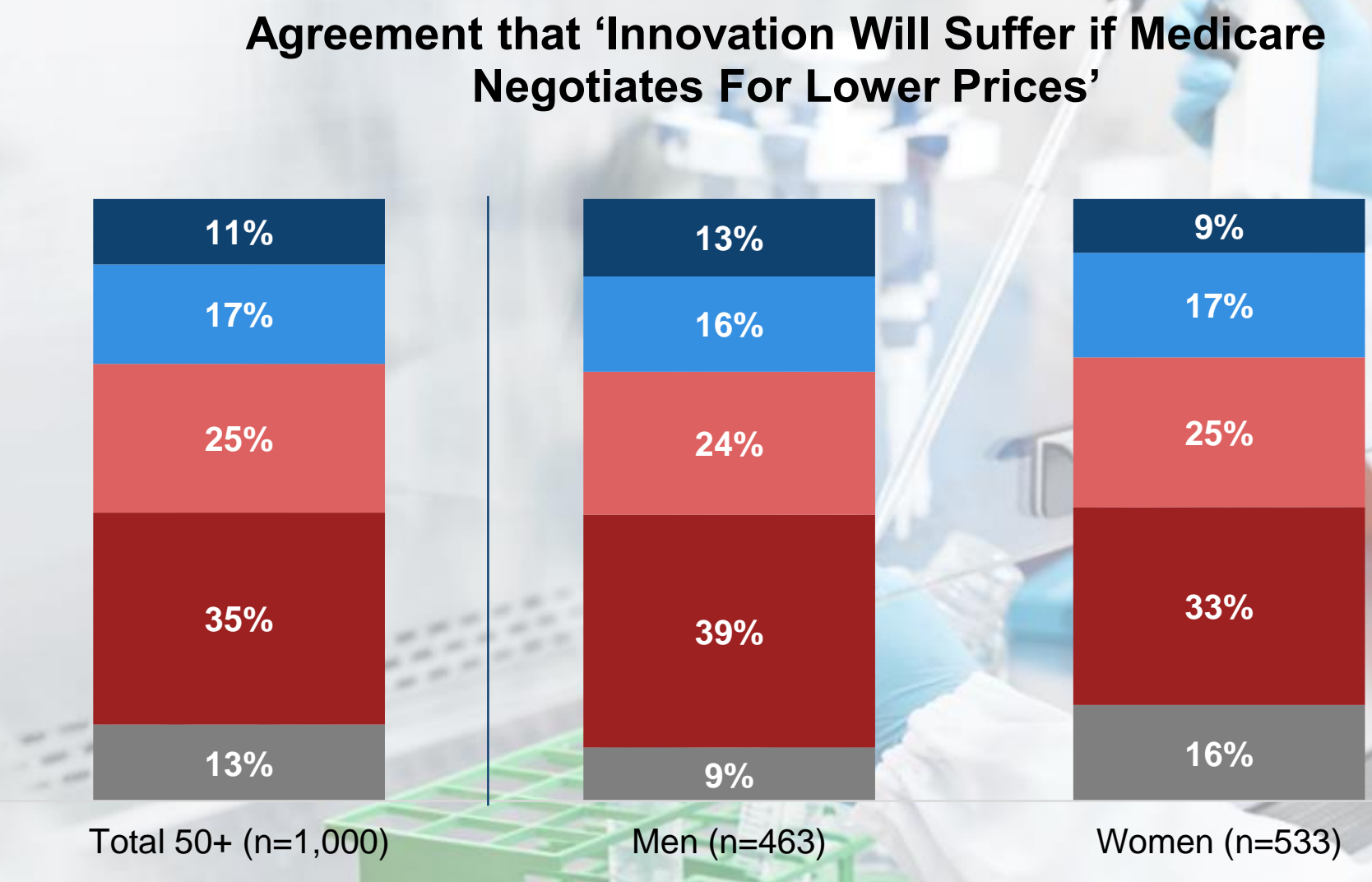

- Strongly agree

Somewhat agree

Somewhat

disagree

- Strongly disagree

Don't know/

refused

Women $(n=533)$ 
Eight in ten voters $50+$ agree that drug prices can be lowered without harming the innovation of new medicines, with no differences by gender.

\section{Agreement That 'Drug Prices Can Be Lowered Without Harming Innovation Of New Medicines'}

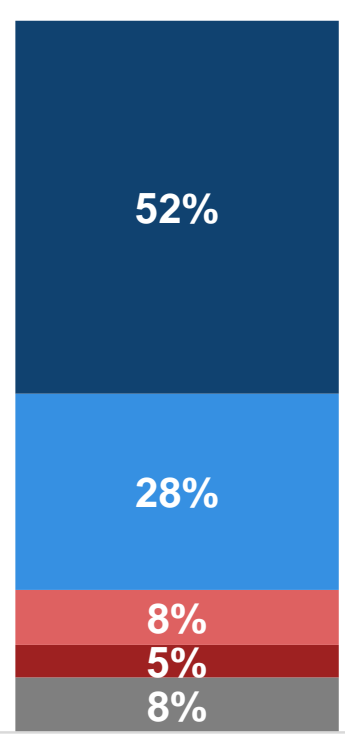

Total $50+(n=1,000)$

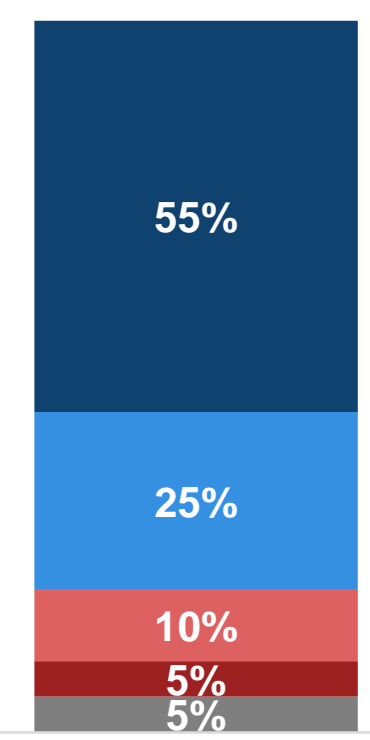

Men $(n=463)$

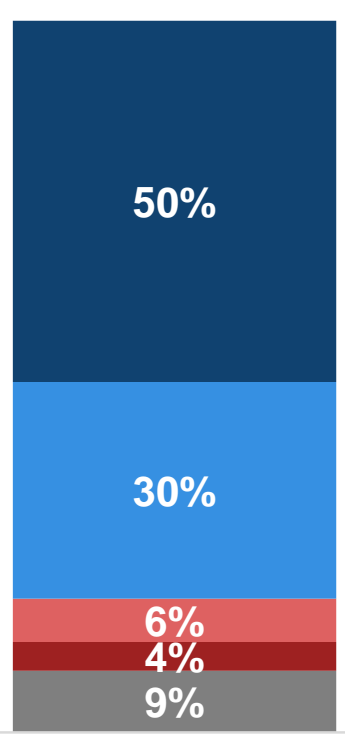

- Strongly agree

- Somewhat agree

Somewhat disagree

- Strongly disagree

- Don't know/ refused

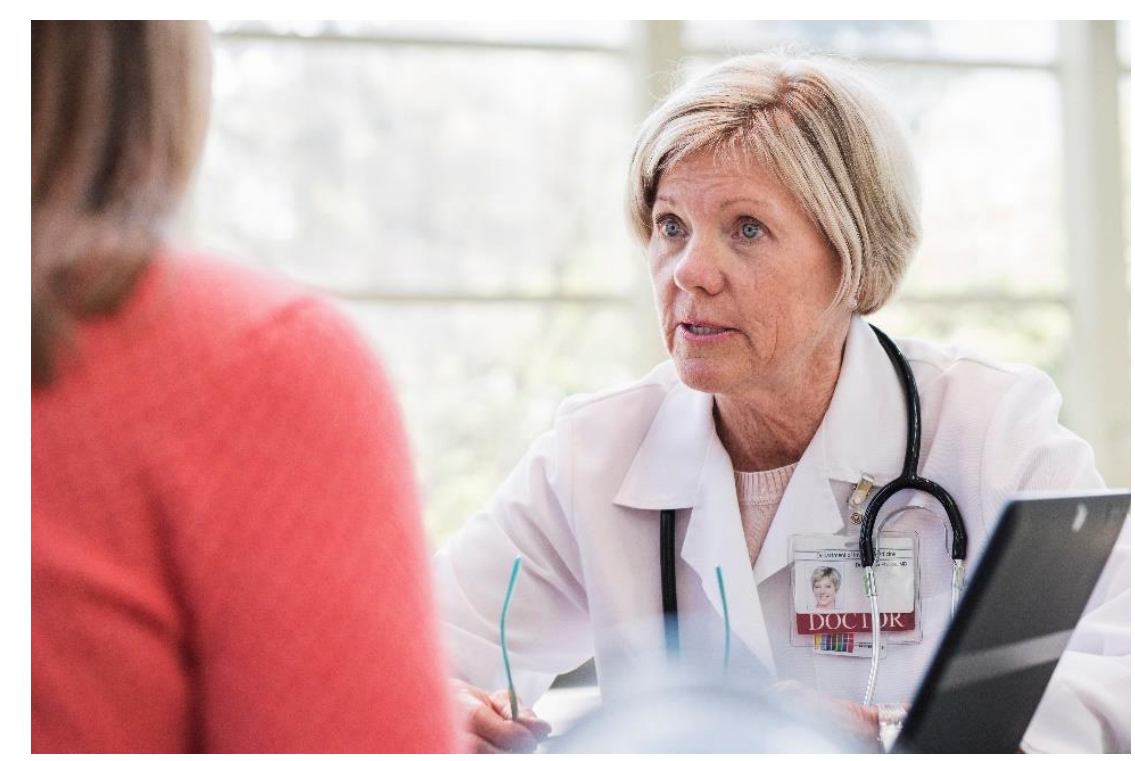

Women $(n=533)$ 
Women more likely than men to strongly or somewhat agree that Congress needs to take action to lower prescription drug prices.

Agreement That 'Congress Needs To Take Action To Lower Drug Prices'

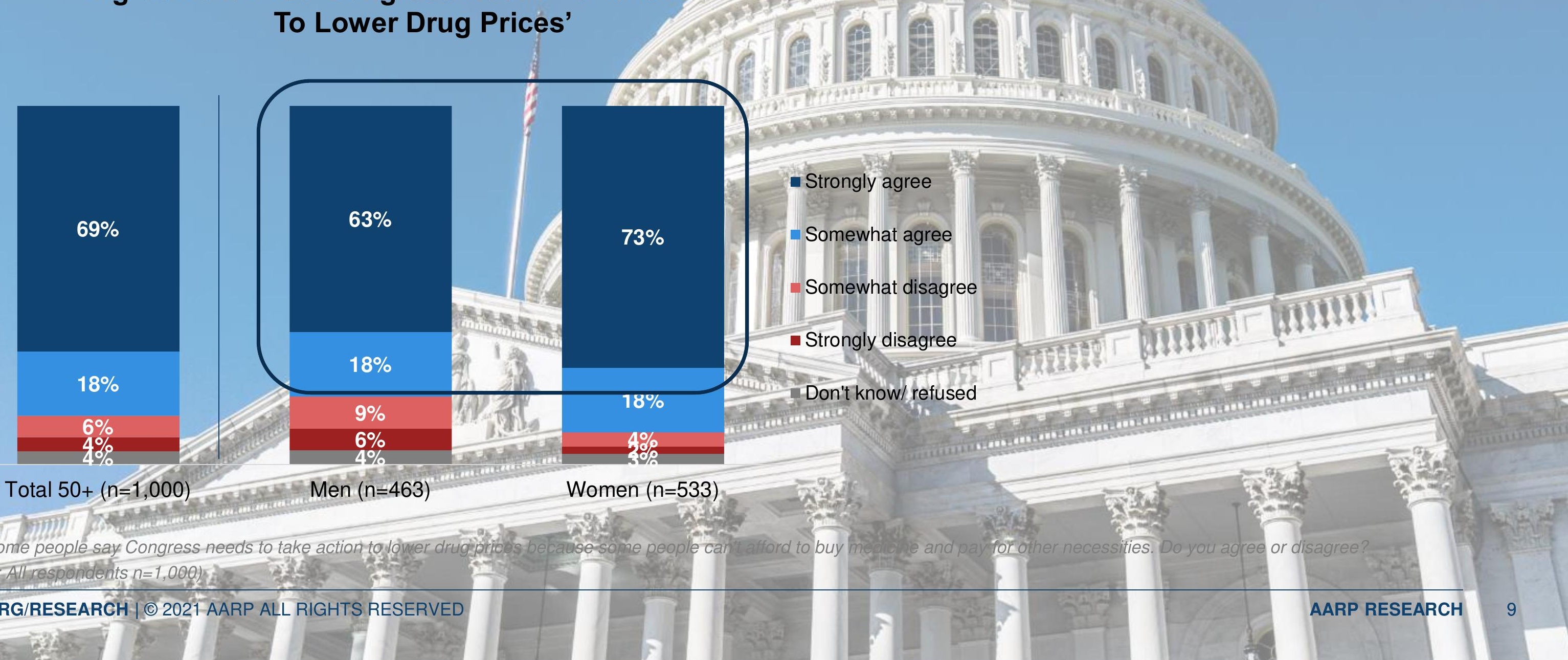




\section{Successful COVID-19 vaccine negotiations increase voters' agreement that government should negotiate for lower prices for other drugs.}

Impact Of Successful COVID-19 Vaccine Negotiations On Agreement That Government Should Negotiate Price For Other Drugs

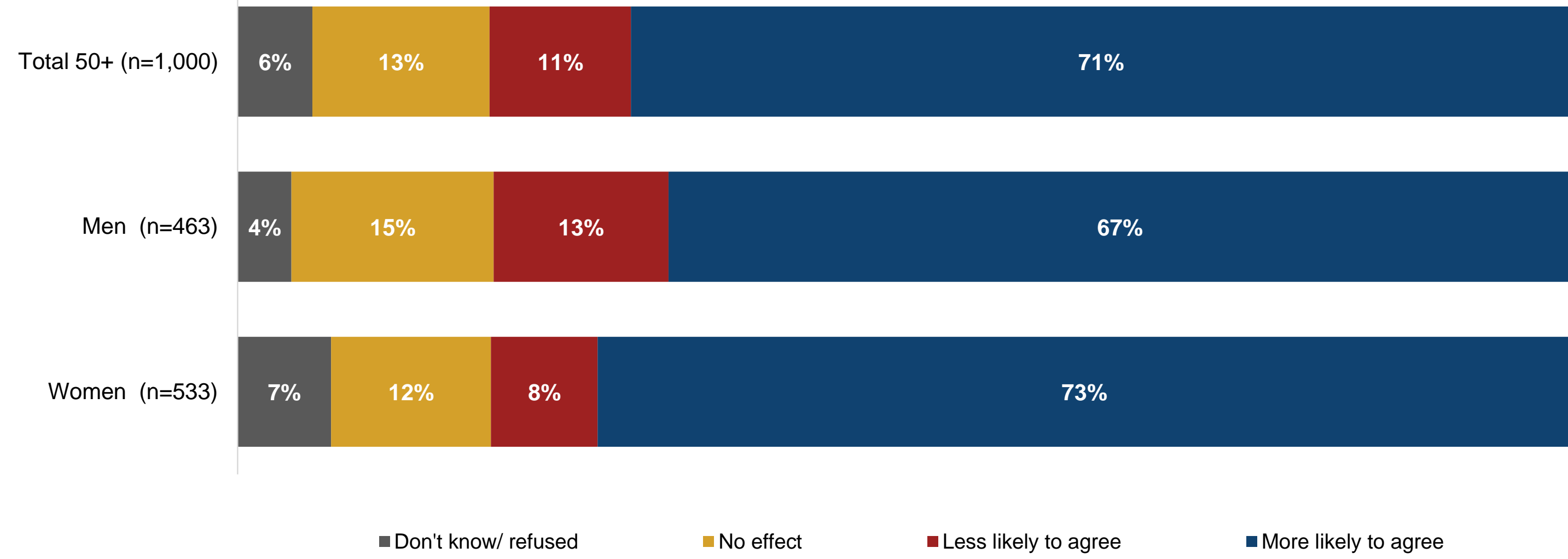




\section{Women voters 50+ more likely to consider Presidential/Congressional}

agreement on lowering Rx drug prices as very or somewhat important.

Importance Of Government Agreeing On Solutions To Lower Drug Prices This Year, by Gender

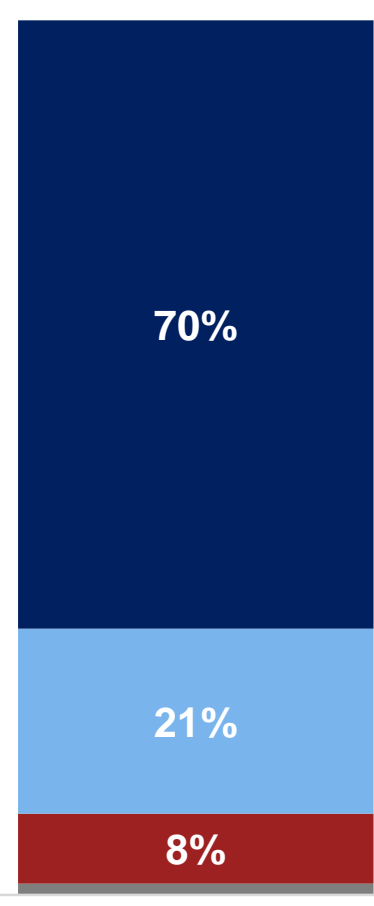

Total $50+(n=1,000)$

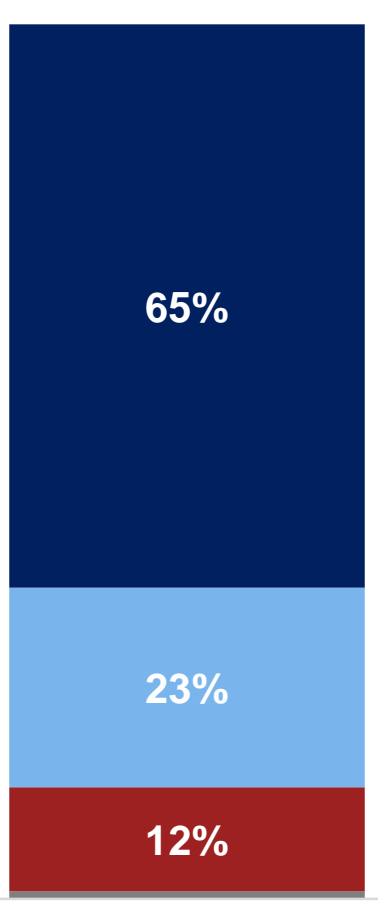

$\operatorname{Men}(n=463)$

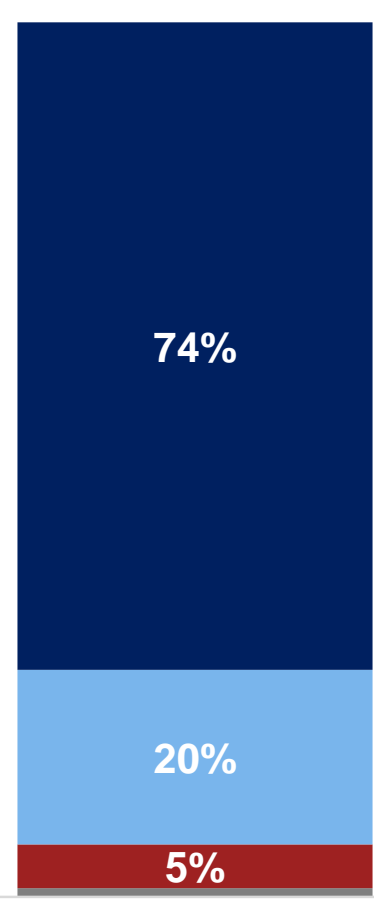

Women $(n=533)$

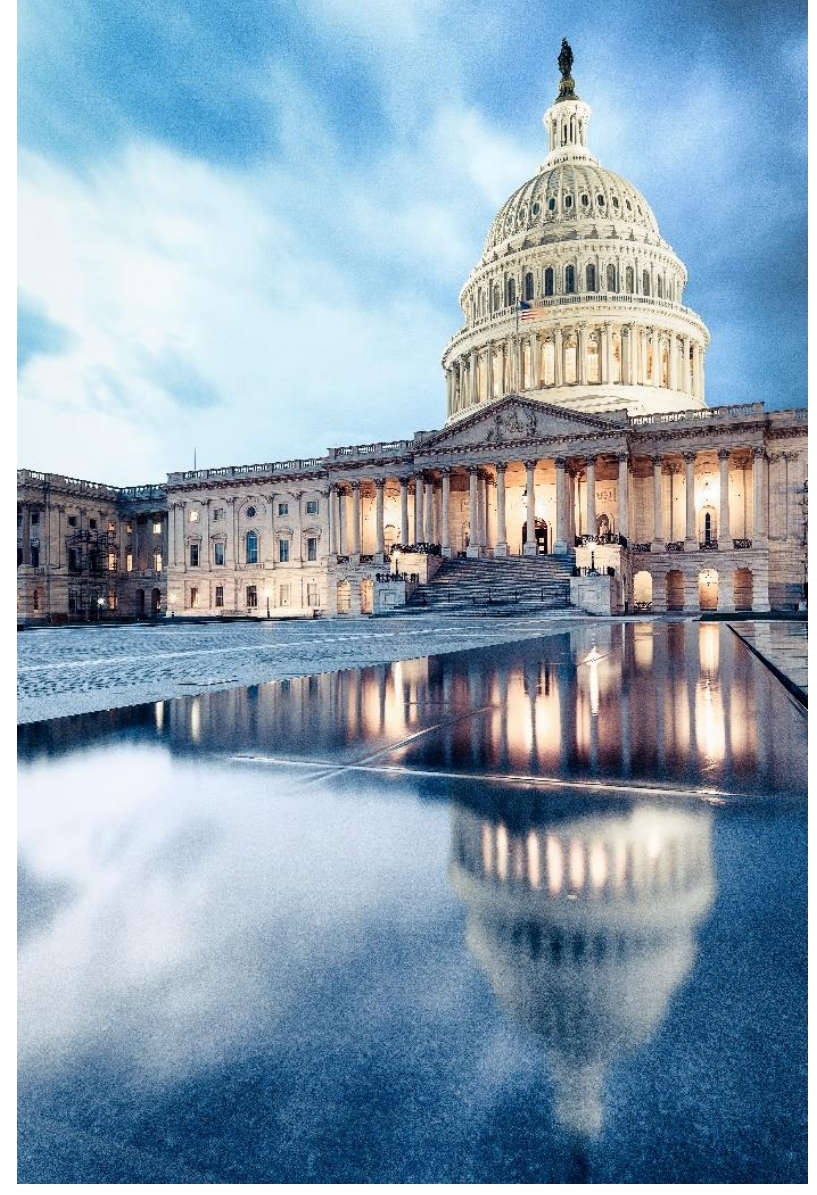


Most voters 50-plus would be more favorable to a member of Congress who supports legislation to lower drug prices, with no differences by gender.

Favorability toward Members of Congress Who Support Legislation To Lower Drug Prices

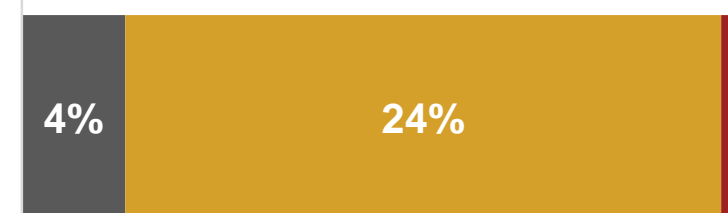

$3 \%$

$26 \%$ 


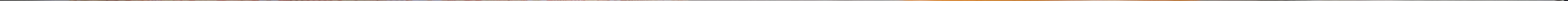




\section{Methodology}

- Objectives: To explore the use of prescription drugs and concerns relating to prescription drugs among United States voters age 50 and older

- Methodology: Phone, nationally representative survey

- Sample: U.S. registered voters age 50 and older $(60 \%$ via landline telephones and $40 \%$ via cell phones); $n=1,605$

- Base sample: $n=1,000$

- Oversamples: $n=404$ African Americans; $n=414$ Hispanic/Latinos

- Interviewing Dates: June 1, 2021 - June 13, 2021

- Language: Interviews conducted in English and Spanish

- Weighting: Data weighted by age, gender, race/ethnicity, and education according to 2019 5-year U.S. Census Bureau American Community Survey (ACS) estimates

- Questionnaire length: 9.6 minutes (average)

- Confidence Intervals: $\pm 3.1 \%$

Note: Some percentages may not equal $100 \%$ due to rounding or the use of multiple response question formats. 
